\title{
Melanocytoma of Optic Disc: Clinical Manifestations, Imaging Characteristics and Follow Up
}

\author{
Rajan Paul ${ }^{*}$, Manoj Kulshrestha, S. Shanmugalingam, Dai Barr \\ Aberystwyth Eye Centre, Hywel Dda University Health Board, Aberystwyth, United Kingdom \\ *Corresponding author: rajan.paul@wales.nhs.uk
}

Received March 12, 2015; Revised March 30, 2015; Accepted April 08, 2015

\begin{abstract}
Melanocytoma of the Optic nerve head, is a benign, stationary pigmented tumor present on or adjacent to the optic disc. Rarely it exhibits minor enlargement and can also undergo malignant transformation to a melanoma. Histopathologically a melanocytoma consists of intensely pigmented round to oval nevus cells with benign features. We report a case of a 77 year old lady with an Optic nerve head melanoma. The clinical features and the imaging characteristics including Ultrasound, Fluorescein angiography and Magnetic resonance imaging are presented.
\end{abstract}

Keywords: melanocytoma, optic nerve head, magnocellular naevus

Cite This Article: Rajan Paul, Manoj Kulshrestha, S. Shanmugalingam, and Dai Barr, "Imaging Characteristics and Follow Up.” American Journal of Medical Case Reports, vol. 3, no. 4 (2015): 113-116. doi: 10.12691/ajmcr-3-4-8.

\section{Introduction}

Melanocytoma, also known as hyperpigmented magnocellularnevus is a variant of melanocyticnevus that has typical clinical and histopathologic features. The predominant cell type in a melanocytoma consists of plump polyhedral nevus cells that contain numerous giant melanosomes while the other cell type are the smaller spindle shaped cells which are lightly pigmented. [1] In addition to occurring in the optic nerve, melanocytoma can also be found in the uveal tract, including the iris, ciliary body, and choroid. We report a case of Optic nerve head $(\mathrm{ONH})$ melanocytoma in an elderly lady.

\section{Case Report}

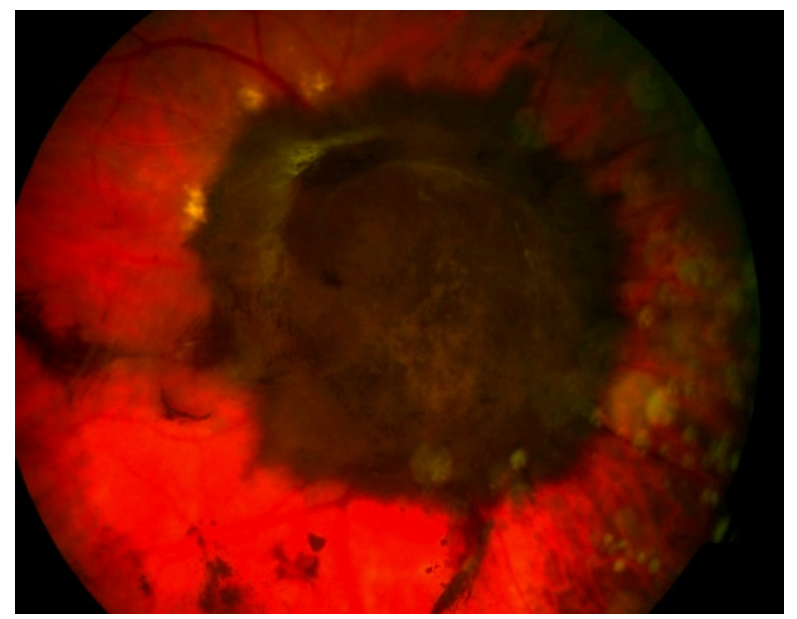

Figure 1. Optic nerve head melanocytoma RE

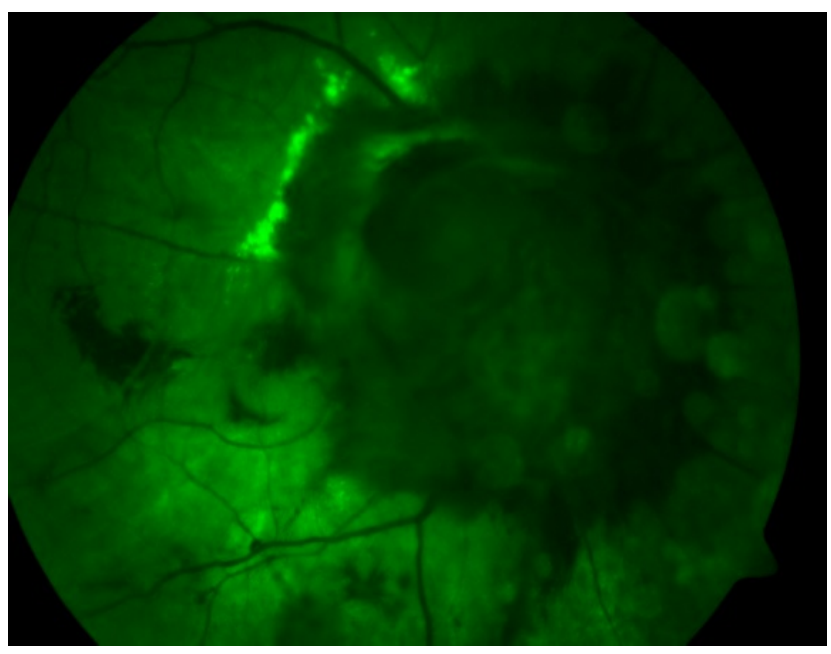

Figure 2. Optic nerve head melanocytoma RE: Red free photograph

A 77 year old lady presented in our clinic with a complaint of diminished vision right eye. She had recently moved to our area and was known to have melanocytoma of the right optic disc and had been treated by Photodynamic therapy for an intralesional haemorrhage in another centre. Although unrelated to this she also had a history of bilateral epiphora. There was no other relevant past ocular or medical history.Her best corrected visual acuity (BCVA) RE: 6/36+1, and LE: 6/9+2. It was noted that the vision RE 3 months back was 6/18 (documented in the previous records). The lower puncta were stenosed bilaterally. Anterior segments were unremarkable and intra ocular pressures (IOP) were RE $16 \mathrm{mmHg}$, LE 16 $\mathrm{mm} \mathrm{Hg}$. Fundus examination under mydriasis revealed a large right optic nerve head melanocytoma with significant thickness, evidence of old exudates and pigment in the vitreous. There was no evidence of neovascularization. Possibility of low grade malignancy 
was not excluded. A Fundus photograph, (Figure 1, Figure 2), Visual fields (Figure 3) Ultrasound (Figure 4), $\mathrm{ONH}$ Optical coherence tomography and Fundus fluorescein angiography were advised. In addition she was put on the list for a bilateral 3 snip procedure.

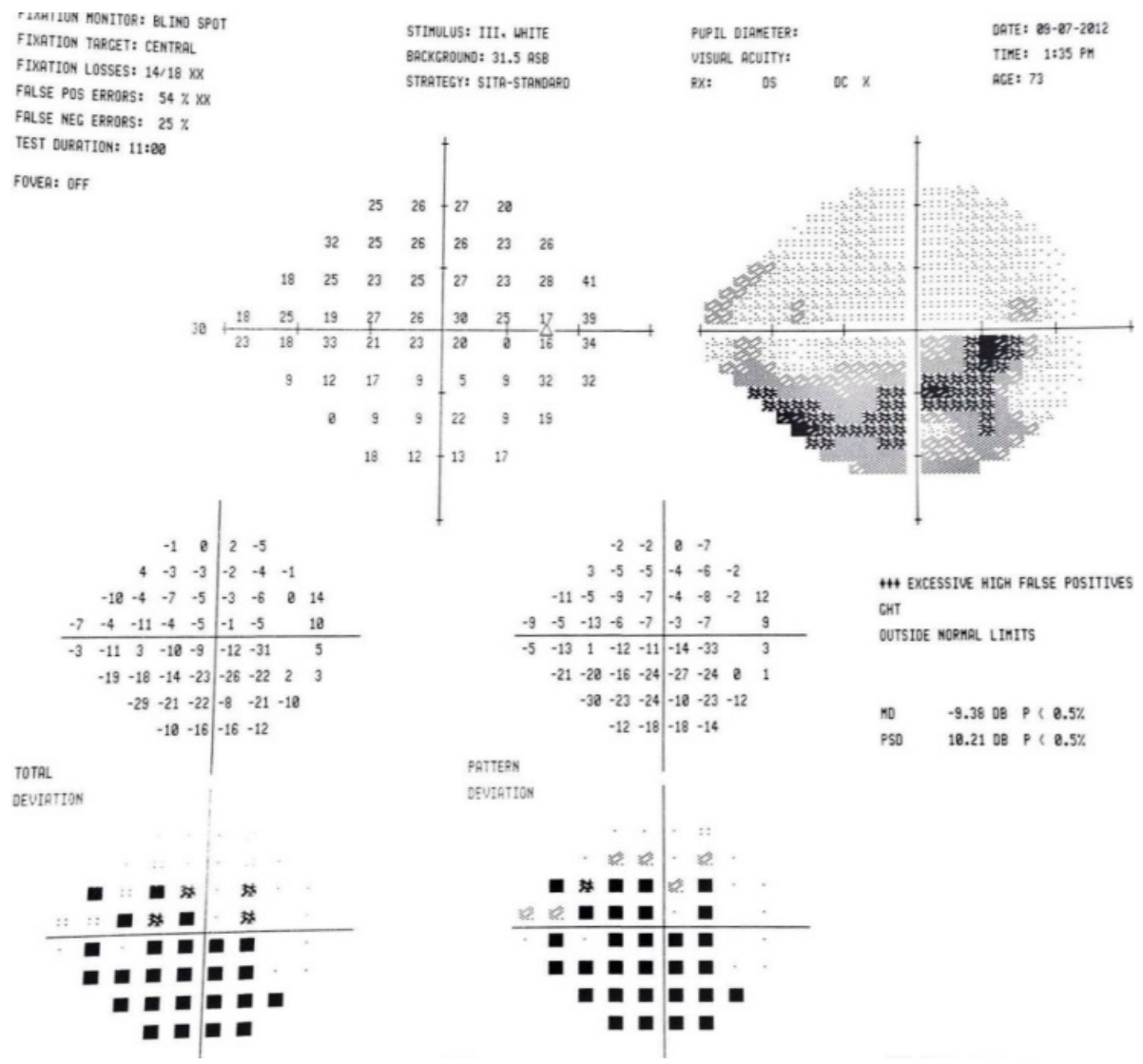

Figure 3. Visual field RE

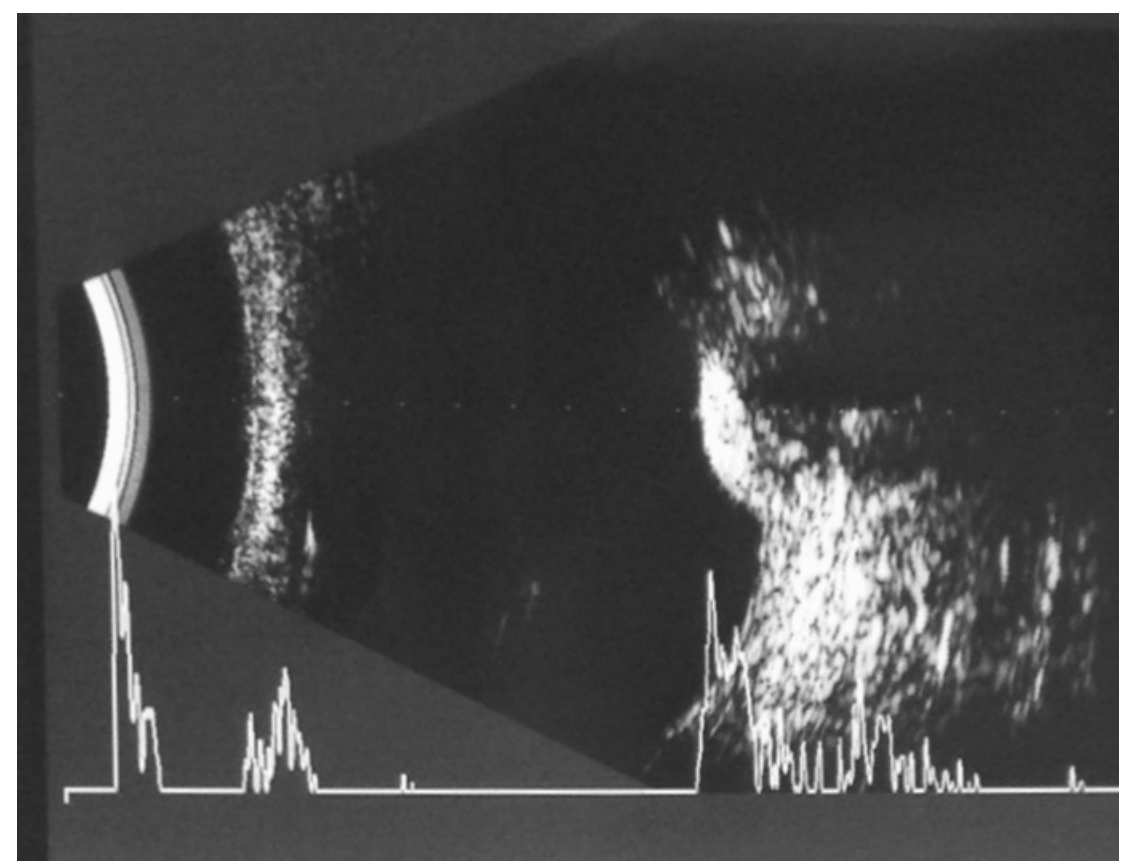

Figure 4. Ultrasound RE

FFA (Figure 5, Figure 6 ) revealed abnormal circulation in the late phase within the ONH mass. Furthermore, there was evidence that this intra papillary circulatory network was incompetent with areas of leakage. OCT revealed submacular fluid and some vitreomacular traction which was likely due to a combination of the exudative process and local laser which was applied in the past.
Comparison of the fundus photos with the old photos revealed no change in the dimensions of the lesion, except for a little more pigment in the vitreous, owing to the fact that the patient had detached her vitreous in that area.

An MRI of the orbits (Figure 7 \& Figure 8) revealed no evidence of periorbital or intracranial spread of the $\mathrm{ONH}$ melanocytoma. 


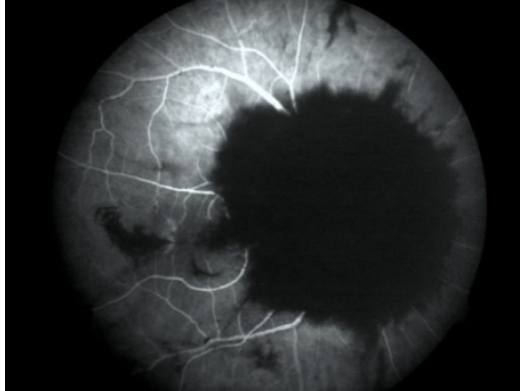

Figure 5. FFA: early phase

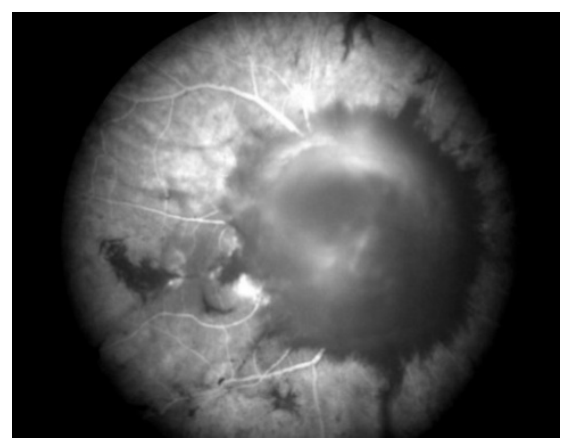

Figure 6. FFA showing abnormal intrapapillary capillary network with a 'blush' in the later phases

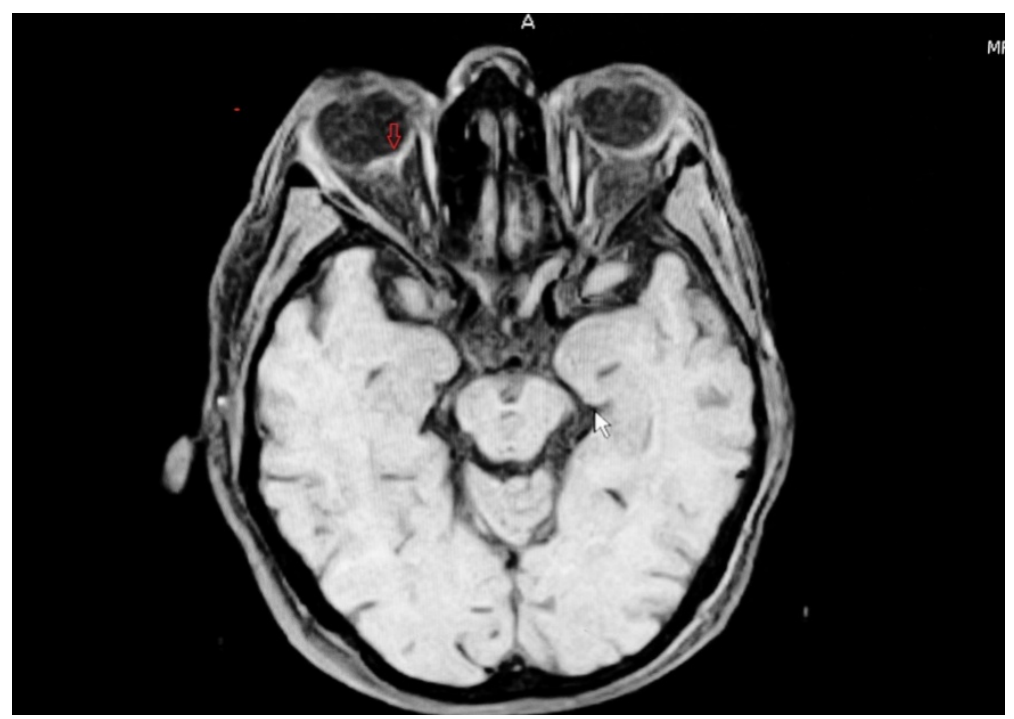

Figure 7. MRI Right Orbit with contrast: The melanocytoma is highlighted

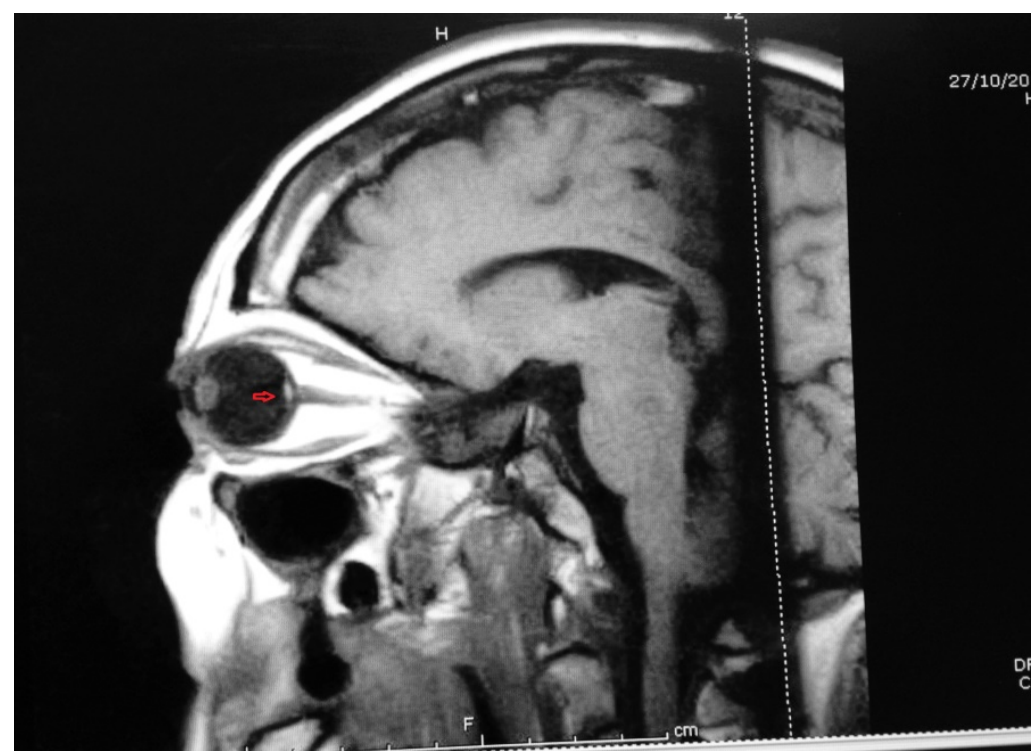

Figure 8. MRI Right Orbit : Sagittal view : No periorbital or intracranial spread.

A life long follow up has planned. She has been periodically reviewed by us for 4 years now with no evidence of extension or further visual impairment.

\section{Discussion}

ONHmelanocytomais a rare benign tumor with rare growth, malignant transformation and visual impairment.
It was believed to be a malignant neoplasm until Zimmerman in 1962, declared it to be a benign tumour and coined the term optic disc melanocytoma, [2] Cogandefined it asoptic nerve magnocellular nevus [3]

Melanocytoma of the $\mathrm{ONH}$ is a hamartoma which consists of large round or oval heavily pigmented melanocytes packed closely and located among axons in the optic disc, anterior optic nerve and in the peripapillary retina [4]. 
The lamina cribrosa of the optic nerve head, with its population of melanocytes, is the origin of these pigmented lesions on the optic nerve [5].

As seen in our case they appear as dark brown or black pigmented lesions with feathery margins due to infiltration into the adjacent retina. Some patients have afferent pupillary and nerve fibre bundle defects possibly due to nerve fibre layer compression.

Zimmerman has reported occurrence of a sudden fall in vision with papillitis and retinal hemorrhages due to ischemic necrosis in a case of melanocytoma [5]. Most melanocytomas are aymptomatic however, mild vision loss can be seen in about $25 \%$ of cases. [6] Retinal extension of the lesion and macular subretinal fluid are risk factors for visual loss. Although rare, severe visual loss can occur as a consequence of central retinal vascular occlusion, spontaneous tumour necrosis or malignant transformation. [6,7] Visual loss by presumed anterior ischemic optic neuropathy and optic atrophy has also been reported $[8,9]$.

Periodic ocular examination is advised in all cases.A study by Lee, Bae et al revealed tumor growth $0 \%$ at 1 year, $14 \%$ at 5 years, and $57 \%$ at 8 years.[10], in another study minor tumor enlargement occurred in $11 \%$ of patients by 5 years and in 32\% of patients by 10 years. Malignant transformation was documented in 2 patients (2\%) [6].

\section{Conclusion}

Traditionally melanocytoma of the $\mathrm{ONH}$ was considered to be a benign, stationary tumor however, it is now known to possesses potential for growth and malignant transformation.

Also, when associated with complications like ischemic tumor necrosis, growth, transformation to a malignant melanoma, central retinal vascular obstruction, retinal extension and subretinal macular exudation, it can be a significant threat to vision.

Careful evaluation, periodic ocular examination and a long term follow up as in our case is therefore advised in all patients with melanocytoma of the $\mathrm{ONH}$.

\section{Conflict of Interests}

The authors declare that there is no conflict of interests regarding the publication of this paper.

\section{References}

[1] Juarez CP, Tso MO. An ultrastructural study of melanocytomas (magnocellular nevi) of the optic disk and uvea. Am J Ophthalmol. $1980 \mathrm{Jul} ;$ 90(1):48-62.

[2] Zimmerman LE, Garron LK. Melanocytoma of the optic disc. Int Ophthalmol Clinic 1962;431-440.

[3] Cogan DG.Discussion; pigmented ocular tumors. En: Boniuk M., editors. Ocular and adnexal tumors. New and controversial aspects. St. Louis: CV Mosby Co.; 1964. 385.

[4] Sehu KW, Lee WR. Ophthalmic Pathology: An illustrated guide for clinicians; 1st edition. Oxford: Blackwell Publishing; 2005 pp. 255-255.

[5] Zimmerman LE. Melanocytes, melanocytic nevi, and melanocytoma. Invest Ophthalmol 1965;4:11-41.

[6] Shields, J. A. et al. Ophthalmology 2004; 111(9):1739-1746.

[7] Shields JA, Shields CL, Eagle RC, Singh AD, Berrocal MH, Berrocal JA. Central retinal vascular obstruction secondary to melanocytoma of the optic disc. Arch Ophthalmol 2001; 119: 12933.

[8] Usui T, Shirakashi M, Kurosawa A, Abe H, Iwata K. Visual disturbance in patients with melanocytoma of the optic disc. Opthalmologica 1990; 201: 92-8.

[9] Saba Al-Rashaed, Emad B. Abboud, and Sawsan R. Nowilaty. Characteristics of Optic Disc Melanocytomas Presenting with Visual Dysfunction. Middle East Afr J Ophthalmol. 2010 Jul-Sep; 17(3): 242-245.

[10] Lee CS1, Bae JH, Jeon IH, Byeon SH, Koh HJ, Lee SC Melanocytoma of the optic disk in the Korean population. Retina. 2010 Nov-Dec; 30(10):1714-20. 